\title{
Influence of land use on total suspended solid and dissolved ion concentrations: Baton Rouge, Louisiana area
}

\author{
DOUGLAS CARLSON
}

Louisiana Geological Survey, Louisiana State University, Baton Rouge, Louisiana, USA dcarlson@1su.edu

\begin{abstract}
Past studies in the Baton Rouge, Louisiana area considered streamwater quality during storm events but ignored water quality during low flow periods. This study includes determination of streamwater quality during low flow time periods for none watersheds in East Baton Rouge Parish, Louisiana. These samples were collected during dry-low flow periods as indicated by water levels at USGS stream gauging sites for each stream. Chemical analysis for ions was completed using colorimeters and gravimetric analysis for total dissolved solids (TDS) and total suspended solids (TSS). Land use appears to impact concentrations of ions, TDS and TSS in a variety of ways during periods of low flow. The two most rural watersheds, which are mainly underdeveloped, have higher concentrations of Fe and $\mathrm{Mn}$. By contrast the three most urban watersheds, that are mainly commercial, industrial or residential, have higher concentrations of $\mathrm{Si}$, $\mathrm{SO}_{4}$ and $\mathrm{TDS}$.
\end{abstract}

Key words land use; ion concentrations; TDS; TSS

\section{INTRODUCTION}

All of the watersheds lie within East Baton Rouge Parish (Fig. 1), in southeastern Louisiana, USA, and have areas of less than $100 \mathrm{~km}^{2}$. For each watershed in Fig. 1, the observation points where water quality samples were collected are shown, and with some USGS stream gauging stations.

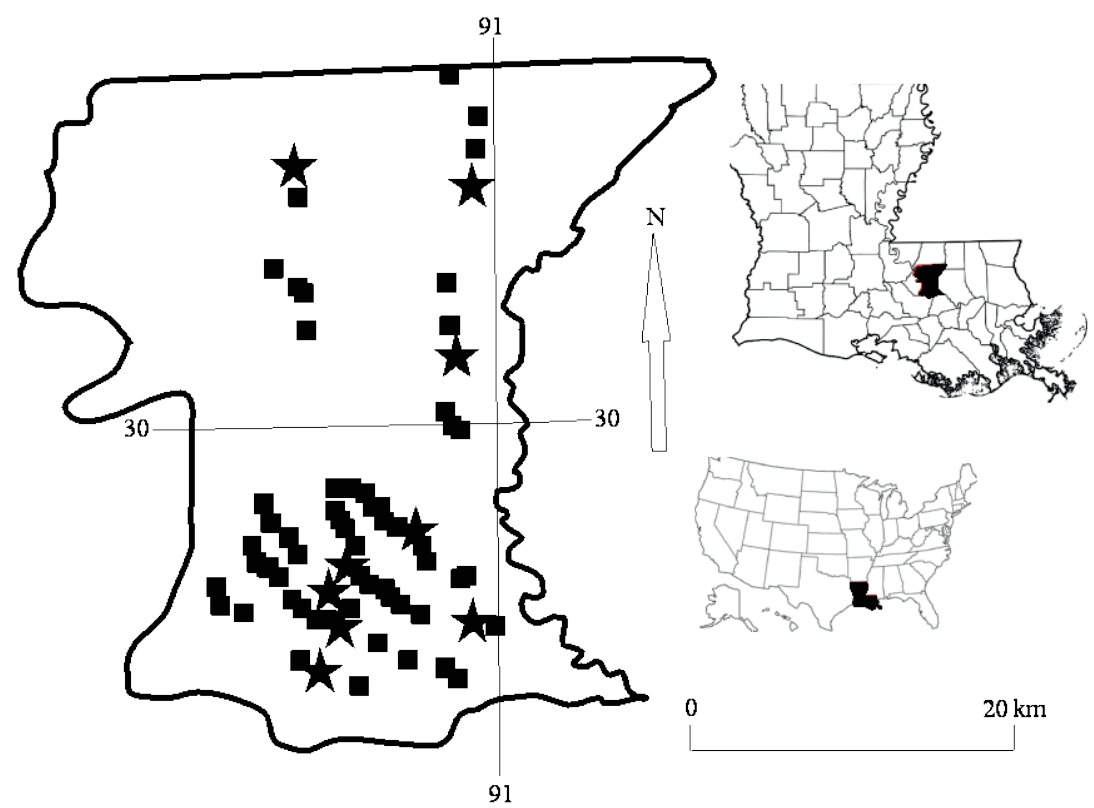

Fig. 1 Location of study sampling sites, samples for water quality are located squares and stars, and sites that are stars are sites of USGS stream gaging sites for discharge measurements.

A number of studies indicate that not only does urbanization cause discharge volumes to change, but will also impact on streamwater quality (Rose \& Peter, 2001; Christian et al., 2011; and Hogan et al., 2014). For East Baton Rouge Parish there is very little past work in regards to water quality of streams. Most such works, like the discharge studies, are focused on streamwater quality during flood events (Demcheck et al., 1998; Frederick, 2003, 2011). These studies considered only five sites that lie in the following watersheds: Beaver Bayou (1 site) Clay Cut Bayou (1 site), North Branch of Ward Creek (3 sites). Except for the site in Beaver Bayou, all are 
very small sub-catchments of a watershed and range in size from 0.25 to $2.23 \mathrm{~km}^{2}$ (Demcheck et al., 1998; Frederick, 2003, 2011). By comparison this study's watersheds range in size from 8.28 to $39.12 \mathrm{~km}^{2}$. There appears to be only one study of Bayou Duplantier that considered water quality during low flow. Low flow conditions tend to dominate the discharge conditions. These conditions should be of interest because wildlife in the streams must live with water levels that are low most of the time rather than deal with chemical environment during flood events. Low flow conditions, those within $0.3 \mathrm{~m}$ of the lowest level, occur on average $78 \%$ of the time. This study is focused on water quality during those low flow conditions and the impact of land use.

\section{METHODS}

The determination of the land use and the extent of watersheds are those as defined by East Baton Rouge Parish City-Parish Planning Commission (2013, 2014). Partial watershed maps were copied at a scale $117 \%$ greater and overlain on the land-use map and a point count was completed similar to what is typically done with a mineral or pore count for a thin section. The point count grid was $0.5 \mathrm{~cm}$ on the map and represents $230 \mathrm{~m}$ in the real world. This allows for compiling hundreds of individual points; land-use category as noted by East Baton Rouge Parish City-Parish Planning Commission (2014) was summed for each of the nine watersheds.

The analytical values were completed in two different manners. The values of TDS and TSS were determined using gravimetric analysis after the sample was filtered through a 1.2 micro filter. Then both a sample of a beaker, filter and residual was heated, and a beaker and water were heated. The changes of mass where noted for each set of beakers and the resulting TDS and TSS were calculated. The ion concentrations in this study were determined with a series of colorimeters. In general, these meters involve measuring the amount of light absorbed for a blank versus that for a sample with a color indicator added to it. The difference of light absorption was converted within the instrument into a value of concentration in $\mathrm{mg} / \mathrm{L}$. The focus of this study is on the ions that typically yield concentration values that almost always occur in detectable concentrations.

\section{RESULTS}

The nine watersheds considered in this study range from ones with a large share of land covered by high density development such as commercial, industrial, institutions, medium and high density residential, offices and utilities, to others where the land is mainly undeveloped (Table 1). Instead of considering urbanization impact through time for a single watershed or a few, this study considers the impact of urbanization on water quality by using a snapshot of development through a series of watersheds at different points in terms of changes from relatively natural land cover to highly altered urban landscape.

The focus of the study is on three ions: iron, phosphate and sulfate, and two parameters: TDS and TSS. The strongest correlation of streamwater quality with land use appears to be concentrations of iron. There is a clear increase in iron concentration with increasing share of land that is either park or undeveloped land (Fig. 2). This study's results appear to be similar to the Christian et al. (2011) study in that urbanization tends to decrease iron concentrations. By contrast Paul \& Meyer (2001) observed that urbanization increases iron concentrations; this was also true for most of the 30 studies included in Das et al. (2009). Maybe in this area water acidity is more important than land use. Das et al. (2009) noted that increases in acidity tends to increase iron concentrations in lakes, so maybe this is happening to the set of streams in the study area. In this area both of these landscapes are largely tree covered-forest landscapes, which in this case is pine and hardwood mix forest (Smith, 1999). Forest landscapes will tend to have more acidic soil for water to infiltrate through (Jobbagy \& Jackson, 2003), which in turn yields a greater solubility of metals, for example iron (Crivineanu et al., 2012). Das et al. (2009) noted that soil, geology, topography and vegetation can also influence iron and manganese concentrations in addition to land use. Rural forested landscapes have significantly higher concentrations of total organic carbon 
Table 1 Land use by category for nine watersheds included in study.

\begin{tabular}{|c|c|c|c|c|c|c|c|}
\hline \multirow[b]{3}{*}{ Watershed(n) } & \multicolumn{7}{|c|}{ Land use categories } \\
\hline & \multicolumn{2}{|c|}{ Low density } & \multicolumn{2}{|c|}{ Medium density } & \multicolumn{2}{|c|}{ High density } & \multirow[b]{2}{*}{ MHDR } \\
\hline & $\mathrm{P}$ & UD & $\mathrm{AG}$ & LDR & COI & IU & \\
\hline Bayou Fountain (1237) & $5 \%$ & $31 \%$ & $20 \%$ & $25 \%$ & $13 \%$ & $0 \%$ & $7 \%$ \\
\hline Beaver Bayou (597) & $3 \%$ & $24 \%$ & $6 \%$ & $61 \%$ & $6 \%$ & $0 \%$ & $0 \%$ \\
\hline Clay Cut Bayou (447) & $2 \%$ & $14 \%$ & $0 \%$ & $48 \%$ & $29 \%$ & $1 \%$ & $6 \%$ \\
\hline Dawson Creek (765) & $3 \%$ & $9 \%$ & $0 \%$ & $45 \%$ & $33 \%$ & $0 \%$ & $9 \%$ \\
\hline Jones Creek (913) & $4 \%$ & $14 \%$ & $0 \%$ & $44 \%$ & $25 \%$ & $4 \%$ & $9 \%$ \\
\hline Little Sandy Creek (1083) & $0 \%$ & $54 \%$ & $29 \%$ & $16 \%$ & $1 \%$ & $0 \%$ & $0 \%$ \\
\hline North Branch of Ward Creek (350) & $5 \%$ & $3 \%$ & $0 \%$ & $54 \%$ & $29 \%$ & $0 \%$ & $8 \%$ \\
\hline Ward Creek* (2053) & $3 \%$ & $15 \%$ & $1 \%$ & $43 \%$ & $28 \%$ & $1 \%$ & $8 \%$ \\
\hline White Bayou (577) & $2 \%$ & $51 \%$ & $17 \%$ & $29 \%$ & $0 \%$ & $0 \%$ & $1 \%$ \\
\hline
\end{tabular}

Abbreviations for land use categories: AG for agricultural use; COI for commercial, office and institutional; IU for industrial and utilities; LDR for low density residential; MHDR for medium and high density residential; P for Park, UD for undeveloped. Numbers may not sum to $100 \%$ because of rounding individual categories to nearest percent. The (n) is the number of observation points used in point count for land use within a watershed.

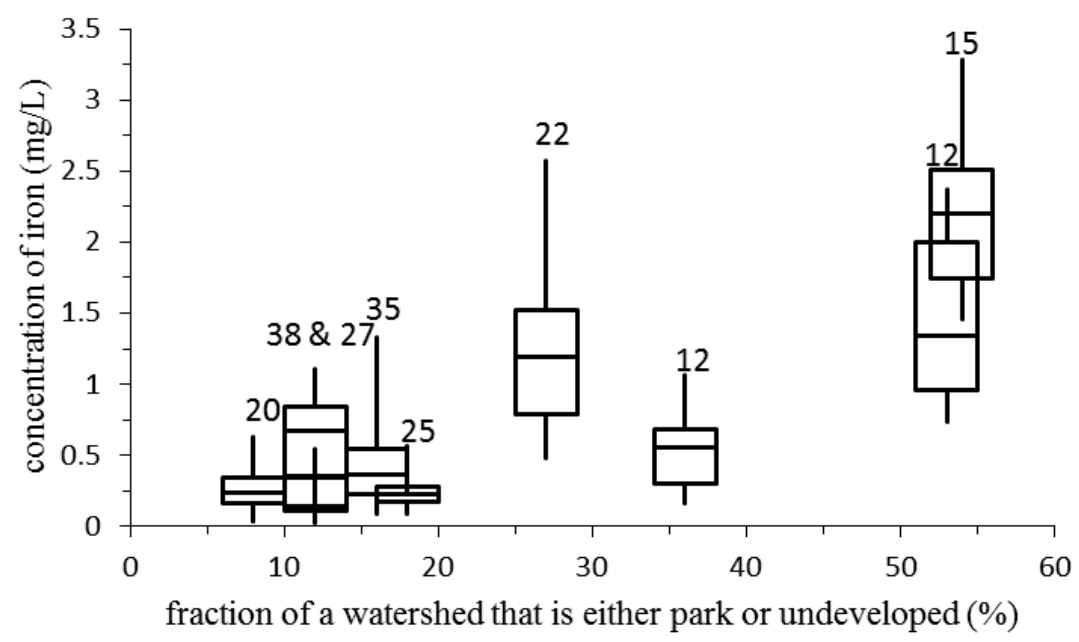

Fig. 2 Iron concentrations for low flow conditions as a function of land use, number of observations for each watershed is number above the top whisker.

(Mallin et al., 2009), which in turn can increase iron concentration (Salminen et al., 2005). This may explain why iron concentration is highest for watersheds with the largest share of undeveloped forest land in the study area.

This study's results for manganese appear to be similar to those for iron in that the manganese concentrations are highest where the watershed has the largest share of undeveloped land (Little Sandy Creek); the median concentration of manganese is $1.02 \mathrm{mg} / \mathrm{L}$ while the watershed with the least area of undeveloped land (North Branch of Ward Creek) has the lowest median concentration of manganese, $0.075 \mathrm{mg} / \mathrm{L}$. Similar results appear to be the case for aluminum too; the highest median value of aluminum concentration is for Little Sandy Creek, $0.03 \mathrm{mg} / \mathrm{L}$, and lowest for North Branch of Ward Creek, $<0.01 \mathrm{mg} / \mathrm{L}$.

For this study the nutrient that is the focus is phosphate concentration. The concentration during low flow conditions appears to increase with the fraction of land that is park or undeveloped up to approximately $35 \%$ of land use, then decrease with even larger share of land use (Fig. 3). So, unlike iron the direct relationship to land use is not with forest cover, but with something else. Others have observed that both urban development and agricultural land use impact concentration of nutrients in a positive manner (Booth \& Reinelt, 1993; Faulkner, 2004). 


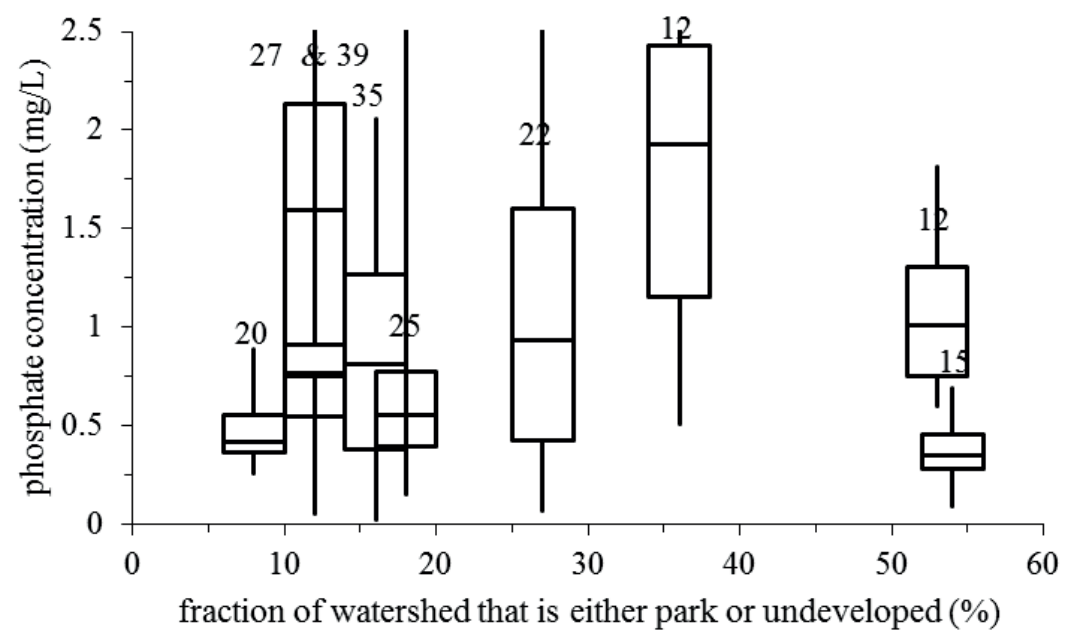

Fig. 3 Phosphate concentrations for low-flow conditions as a function of land use, number of observations for each watershed is number above the box.

However, some studies have indicated that urbanization does not significantly impact concentrations of either nitrates or phosphates (Hickman \& Fischer, 2008; O Driscoll et al., 2010).

By contrast, some note that urbanization has a stronger correlation with nutrient and pesticide concentrations in streams than even agricultural land (Paul \& Meyer, 2001). For this study area, urbanization is the only land-use category that can be considered because five of the nine watersheds have no agricultural land and only three have more than $15 \%$ of the watershed covered by agricultural land use. So, is urbanization the factor that correlated well with phosphate concentration in streams? There appears to be a peak of phosphate concentration when $35 \%$ of land use is urban. This could be a function of new suburban areas being areas where there is a greater rate of fertilizer application than older and maybe higher density urban development. In the Baltimore, Maryland, area results are similar: a suburban watershed has a higher nutrient concentration than both urban watershed and rural (forested) watershed (Groffman et al., 2004).

The concentration of silicon in streams appears to increase until undeveloped land is approximately $35 \%$ of all land and then declines, a result similar to phosphate. This may indicate areas that are in transition from being mainly undeveloped, or other rural landscapes, to urban. Urban landscapes have the highest silicon concentrations which is probably a result of loss of sand from construction sites being carried into the stream. This pattern is similar to what is occurring with the concentration of TSS as well.

This study's results for sulfate concentrations are similar to others (O'Driscoll et al., 2010) in that urbanizations increases sulfate concentrations. However, in this study the concentration of sulfate appears to be almost independent of land use (Fig. 4). The concentration of sulfate is approximately constant for watersheds that have between $8 \%$ and $36 \%$ of their land covered by park or undeveloped land, and then decrease by over $75 \%$ for two watersheds that have approximately $55 \%$ of their land as park or undeveloped land (Fig. 4). What maybe occurring here is that watershed location is just as important as land use within it. The two watersheds with sulfate concentrations that have concentrations usually under $4 \mathrm{mg} / \mathrm{L}$ lie outside the area between an industrial region that lies along the Mississippi River, which is between the industrial north-side of Baton Rouge and New Orleans. The other seven watersheds are within the two ends of the industrial district that lies along the Mississippi River and usually have sulfate concentrations over $8 \mathrm{mg} / \mathrm{L}$ and often over $15 \mathrm{mg} / \mathrm{L}$. It is possible that a significant portion of sulfate entering the seven watersheds is from dry precipitation from industry rather than direct surface runoff or groundwater for low flow conditions. When considering the distribution of wind throughout the full year, the northern watersheds are downwind only about $23 \%$ to $30 \%$ of the time, while the southern urban watersheds are downwind $45 \%$ to $56 \%$ of the time (WeatherSpark.com, 2014). Wind must be necessary to bring in sulfate that is a result of combustion at factories in the 


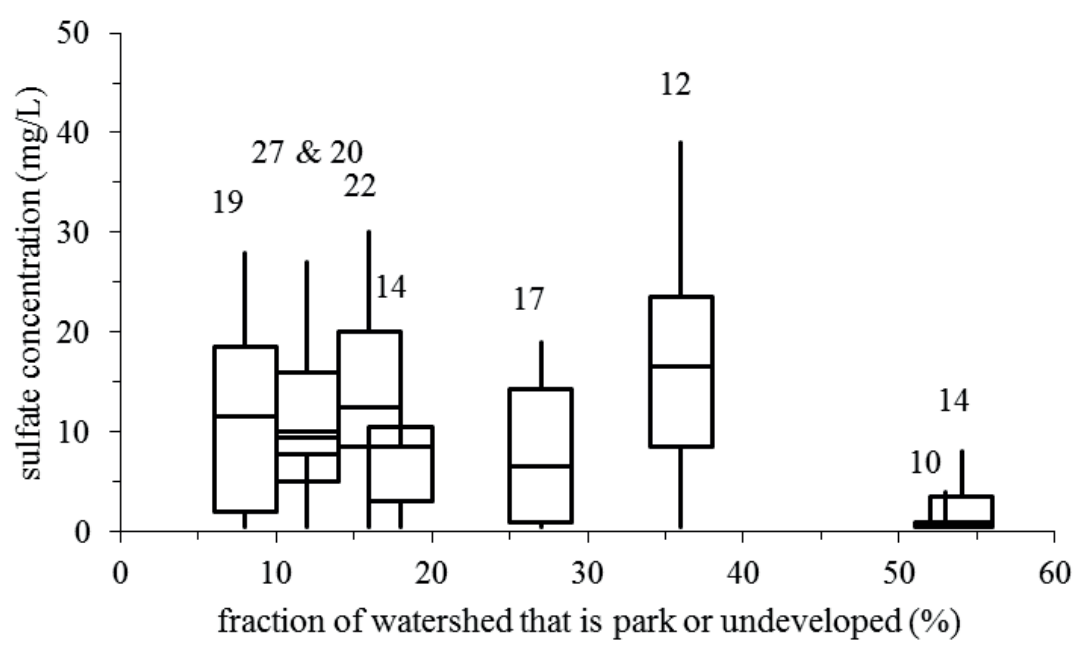

Fig. 4 Sulfate concentration for low flow conditions as a function of land use. Number of observations for each watershed is number above the top whisker.

industrial zone because the shallow aquifer concentrations of sulfate are too low for most of the watersheds. The shallow aquifer in nearby Livingston and Saint Helena parishes has a median sulfate concentration of $2.4 \mathrm{mg} / \mathrm{L}$ (Tomaszwski, 1988), a value below the median value for the five southern urban watersheds, but is similar to the median for two rural watersheds outside the area between the industrial zones.

In general, the TDS of streamwater decreases within increasing share of land that is either park or undeveloped (Fig. 5). So, as landscapes become more urbanized the TDS increases from median values of approx. $100 \mathrm{mg} / \mathrm{L}$ in the rural landscapes of Little Sandy and White Bayou watersheds to median values of $180-240 \mathrm{mg} / \mathrm{L}$ in the five most urban landscapes: Clay Cut Bayou, Dawson Creek, Jones Creek North Branch of Ward Creek, and Ward Creek (Fig. 5). This appears to be similar to what others have observed where TDS increases as urbanization occurs (Paul \& Meyer, 2001). In general, calcium concentrations decrease with an increase in the fraction of land that is either park or undeveloped. So, like TDS it appears that calcium concentration increases with urbanization. This is also similar to what others have noted (Paul \& Meyer, 2001).

The concentration of TSS for the study area streams appears to be nearly independent of the fraction of land that is either park or undeveloped land. This appears to contradict results from other studies that indicate that urbanization tends to increase concentrations of TSS (Mallin et al., 2009). A number of studies note that TSS would increase to highest values for areas that are undergoing development (Mallin et al., 2009). This is observed in the study area where watersheds undergoing more rapid development appear to have typically the highest values: Bayou Fountain, Beaver Bayou, and White Bayou. All of these lie on the growing edge of development within East Baton Rouge Parish, while more established urban watersheds, Clay Cut Bayou, Dawson Creek, Jones Creek, North Branch of Wards Creek, and Ward Creek have lower TSS values. The one watershed beyond the advancing front of suburban development, Little Sandy Creek, also has low values of TSS.

It appears that the correlation of ion concentrations with TSS is usually weak for this study's streams. It appears that the correlation of ion concentrations with TSS is usually weak. This is particularly true for low flow conditions. The correlation coefficients between sulfate and TSS, phosphate and TSS, and TDS and TSS is very weak (Calkins, 2005; and University of Strathclyde, no date) where $r$ is $0.0735,0.052$, and 0.1766 respectively. The correlation coefficient between iron and TSS is weak (bized.co.uk, 2002; and Calkins, 2005) where $r$ is 0.387. Lastly, there is a so-called moderate correlation between silicon and TSS, and manganese and TSS where $r$ is 0.4165 , and $r$ is 0.5318 , respectively (bized.co.uk, 2002; and Ratner, no date). This is to be expected when considering TDS has a value that is on average approximately six times greater 


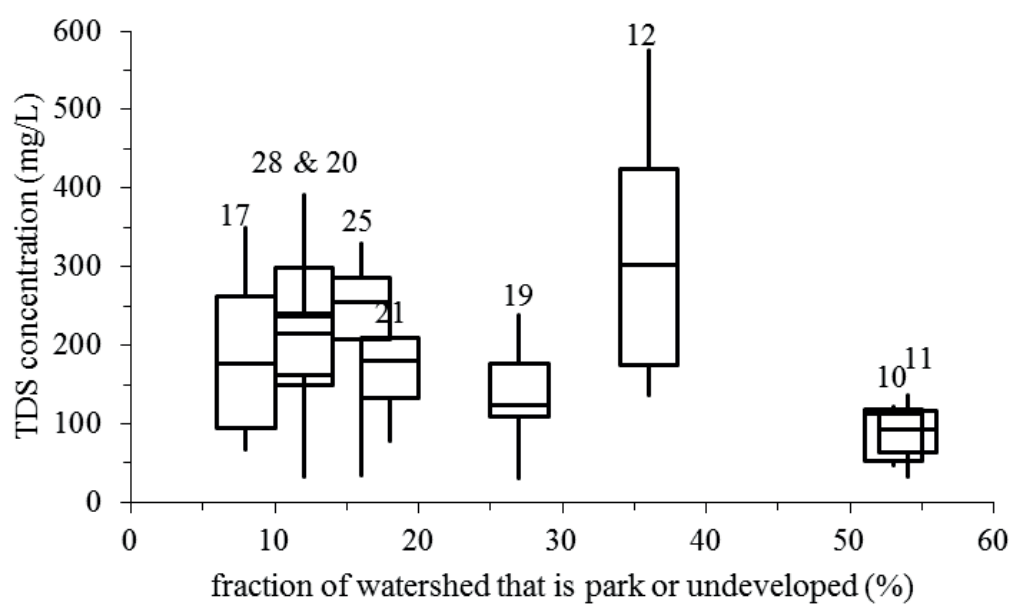

Fig. 5 TDS concentration for low flow conditions as a function of land use. Number of observations for each watershed is number above the top whisker.

than the TSS value when flow conditions are low. As expected when flow is higher, during or soon after flooding, ion concentrations are more strongly correlated with TSS concentrations. For example, in this study the correlation coefficient value between manganese and TSS is strong, $r$ is 0.8012 (bized.co.uk, 2002, Calkins, 2005; Ratner, no date; and University of Strathclyde, no date). For these conditions TDS and TSS concentrations are approximately the same so the fraction of ions adsorbed onto particles would larger than during low flow conditions.

\section{SUMMARY}

This study considered nine watersheds that have differing extents of development from five highly urbanized watersheds where little land $(<15 \%)$ is undeveloped, to two watersheds that are mainly undeveloped, over $50 \%$. There are two watersheds with intermediate development. Land use does appear to impact the resulting ion concentrations in streams. Urbanization in East Baton Rouge Parish impacts ion concentrations in three different ways.

- There is a consistent increase in the concentration of an ion or parameter as watersheds become more urbanized. Examples of this are sulfate and TDS.

- There is an initial increase in concentration of an ion as watersheds becomes more urbanized then a decrease for very highly urbanized watersheds. Examples of this are phosphate and silicon

- There is a consistent decrease in the concentration of an ion as watersheds become more urbanized. Examples of this are iron and manganese.

It appears from consideration of this area's set of nine watersheds that urbanization is but one of a number of factors influencing ion concentrations in streams. Other factors appear to be plant cover and associated $\mathrm{pH}$ of soils, stage within the development from rural undeveloped land to high intensity urbanized landscape, and possibly even position relative to possible airborne sources of ions such as sulfate.

\section{REFERENCES}

Bized.co.uk. (2002) Correlation Explained [TimeWeb]: http://www.bized.co.uk/timeweb/crunching/crunch_relate_expl.htm accessed 9 June 2014.

Booth, D.B. \& Reinelt, L.E. (1993) Consequences of urbanization on aquatic systems-measured effects degradation thresholds and corrective stratgies. Watershed 545-560.

Calkins, K.G. (2005) Applied Statistics-Lesson 5 Correlation Coefficients: http://www.andrews.edu/ calkins/math/edrm611 /edrm05.htm accessed 9 June 2014. 
Christian, L.N., Banne, J.L. \& Mack, L.E. (2011) Sr isotopes as tracers of anthropogenic influences on stream water in the Austin, Texas area: Chemical Geology, 282, 84-97.

Crivineanu, M.F., et al. (2011) Mathematical models describing the relations between surface water parameters and iron concentration. Chemical Bulletin of "Politechnica" University of Timisoara, 57(1), 23-28.

Das, B., Nordin, R. \& Mazumder, A. (2009) Watershed land use as a determinant of metal concentrations in freshwater system. Environmental Geochemical Health 31, 595-607.

Demcheck, D.K., Frederick, C.P. \& Johnson, K.L. (1998) Water-quality characteristics of urban storm runoff at selected sites in East Baton Rouge Parish, Louisiana, April 1993 through June 1995. US Geological Survey Open File Report 98-565.

East Baton Rouge Parish City-Parish Planning Commission (2014) Existing Land Use Map of East Baton Rouge Parish. East Baton Rouge Parish City-Parish Planning Commission, single sheet 1:45,000 scale.

East Baton Rouge Parish City-Parish Planning Commission (2013) Watersheds, Wetlands, and Streams. East Baton Rouge Parish City-Parish Planning Commission, single sheet 1:52,500 scale.

Faulkner, S. (2004) Urbanization impacts on the structure and function of forested wetlands. Urban Ecosystems 7, 89-106.

Frederick, C.P. (2011) Water-Quality Characteristics of Urban Storm Runoff at Selected Sites in East Baton Rouge Parish, Louisiana, February 2006 Through November 2009. US Geological Survey Scientific Investigations Report $2011-5199$.

Frederick, C.P. (2003) Water-Quality Characteristics of Urban Storm Runoff at Selected Sites in East Baton Rouge Parish, Louisiana, February 1998 Through April 2002. US Geological Survey Water-Resources Investigations Report 03-4212.

Gorffman, P. M et al. (2004) Nitrogen fluxes and retention in urban watershed ecosystems. Ecosystems 7, $393-403$.

Hickman, R.E. \& Fischer, J.M. (2008) Water quality of streams in and near the Delaware Water Gap National Recreation Area, Pennsylvania and New Jersey, 2002-04. US Geological Survey Scientific Investigations Report 2007-5290.

Hogan, D.M., et al. (2014) Mitigating the effects of landscape development on streams in urbanizing watersheds. Journal of American Water Resources Association 50(1), 163-178.

Jobbagy, E.G. \& Jackson, R.B. (2003) Patterns and mechanisms of soil acidification in the conversion of grasslands to forest. Biogeochemistry 64, 205-229.

Mallin, M.A., Johnson, V.L. \& Ensign, S.H. (2009) Comparative impacts of stormwater runoff on water quality of an urban, a suburban, and a rural stream. Environ Monit. Assess. doi 10.1007/s10661-008-0644-4.

O'Driscoll, M., et al. (2010) Urbanization effects on watershed hydrology and in-stream processes in the southern United States. Water, 2, 605-648.

Paul, M.J. \& Meyer, J.L. (2001) Streams in the urban landscape. Annual Review of Ecological Systems, 32, $333-365$.

Ratner, B. (no date) The Correlation Coefficient: Definition: http://www.dmstat1.com/res/TheCorrelationCoefficient Defined.html, accessed 9 June 2014.

Rose, S. \& Peters, N.E. (2001) Effects of urbanization on streamflow in the Atlanta area (Georgia, USA): a comparative hydrological approach. Hydrological Processes 15, 1441-1457.

Salminen, R., et al. (2005) Geochemical Atlas of Europe, Part I - Background Information Methodology and Maps: http://weppi.gtk.fi/publ/foregsatlas/ accessed April 2014.

Smith, L. (1999) Historic vegetation of the Florida parishes by parish. Louisiana Natural Heritage Program, Louisiana Department of Wildlife \& Fisheries, Baton Rouge.

Tomaszewski, D.J. (1988) Ground-water hydrology of Livingston, St. Helena, and parts of Ascension and Tangipahoa parishes, southeastern Louisiana. Louisiana Department of Transportation and Development Water Resources Technical Report no. 43.

University of Strathclyde (no date) Correlations: Direction and Strength: http://www.strath.ac.uk/aer/materials/4dataanalysisin Educationresearch/unit4/correlationsdirectionandstrength/ accessed 9 June 2014.

WeatherSpark.com (2014) Average Weather for Baton Rouge, Louisiana, USA. http://weatherspark.com/averages/29816/BatonRouge-Louisiana-United -States accessed 25 March 2014. 